\title{
An experimental study into the geometry of supply-limited dunes
}

\author{
ARJAN P. TUIJNDER, JAN S. RIBBERINK and SUZANNE J. M. H. HULSCHER \\ Department of Water Engineering \& Management, Faculty of Engineering Technology, University of \\ Twente, P.O. Box 217, Enschede, The Netherlands (E-mail: a.p.tuijnder@ctw.utwente.nl)
}

\begin{abstract}
The relationship between dune geometry and the volume of mobile sediment was studied in flume experiments. In these flume experiments, the volume of mobile sediment on top of an immobile coarse sediment layer was increased stepwise and the bedform characteristics were observed. A strong relationship was found between the volume that is mobile - and therefore available for bedform formation - and the dune dimensions and regularity. If the sediment supply is limited, dunes are smaller and more regular. Series of experiments with a decreasing supply limitation were conducted for different flow velocities and water depths. The relationship between the dune dimensions and the available volume is different for each series. The observed relationships between dune dimensions and layer thickness collapse to one relationship for height and one for length if scaling parameters are introduced. Current models for bedform dimensions under alluvial conditions can be extended to partial transport conditions using this relationship.
\end{abstract}

Keywords Bedforms, supply limitation, sand-gravel sediment, fluvial dunes, supply limited dunes, bedform dimensions.

\section{INTRODUCTION}

Bedforms on river beds are important for waterlevel predictions, which are essential to prevent floods and keep rivers navigable. The bedforms especially dunes - are a primary source of roughness and therefore a major factor in determining water levels (Simons \& Richardson, 1966). The hydraulic roughness induced by dunes depends on their dimensions. Therefore, models to predict dune dimensions from flow and sediment characteristics have been formulated (e.g. Gill, 1971; Fredsøe, 1982; Van Rijn, 1984; Zhang, 1999).

These models are based on full mobility conditions, under which the sediment transport is not supply-limited. In the case of a supply limitation, the sediment delivery from upstream is smaller than the local transport capacity, while local entrainment of more sediment is prevented by a layer of immobile sediment. This effect causes a limitation in the volume of mobile sediment from which bedforms can be formed. The unerodable layer may have formed naturally, as can happen when the bed shear stress can transport only a part of the bed sediment (partial transport); or the unerodable layer may be man-made, as an erosion prevention measure. In sand-gravel mixtures, partial transport conditions are common and supply-limited bedforms have been observed (e.g. McCulloch \& Janda, 1964; Whiting et al., 1988; Chiew, 1991; Bennett \& Bridge, 1995; McLelland et al., 1999; Carling et al., 2000; Kleinhans et al., 2002; Blom et al., 2003; Kuhnle et al., 2006; Tuijnder et al., 2007; Dreano et al., 2008). Generally, the supply-limited bedforms that were observed have a lower relief than the bedforms observed in sandy beds, which have alluvial conditions. This observation has implications for the bedform-induced roughness: with reducing bedform dimensions, the bed roughness decreases (Van der Zwaard, 1974; Tuijnder et al., 2007).

To improve the prediction of roughness in morphological models, it would be useful to be able to predict the bedform dimensions under 


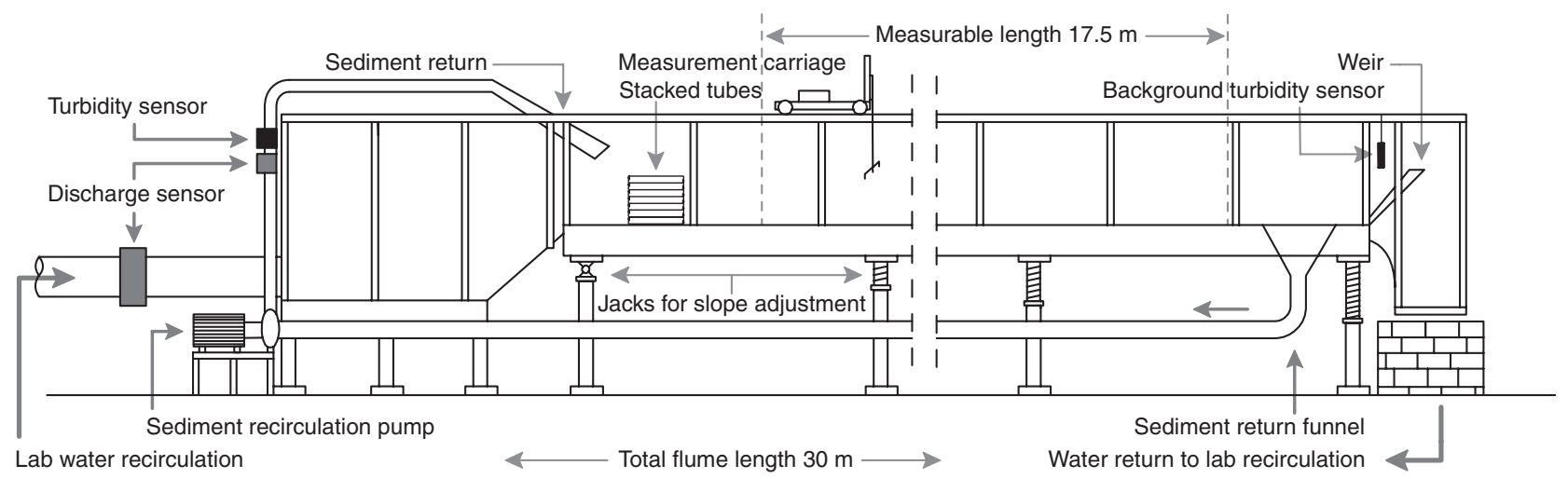

Fig. 1. Side view of the used flume set-up. The supply of water came from a constant-head tank ca $5 \mathrm{~m}$ above the level of the flume. The flume is supported by jacks that allow the flume to be tilted to realize an equilibrium flow.

supply-limited conditions. Therefore, flume experiments were conducted to study the dependency of the dune dimensions on the supply limitation. The set-up of these experiments is explained in the Experimental set-up section. In these experiments, the intention was to study the relationship between the sediment availability and the characteristics - especially the average length and height - of the bedforms that developed. The results of these experiments are presented in the Experimental results section. In the section Empirical relationship between dune dimensions and supply limitation, scaling parameters are proposed to describe the observed variation in bedform dimensions with the varying supply limitation. In the final two sections, the results are compared with previous observations of bedforms under supply-limited conditions and the conclusions from this study are presented.

\section{EXPERIMENTAL SET-UP}

The dependency of the geometry of a dune on the supply limitation was studied in experiments in a sediment-recirculating flume (Fig. 1). The flume had a width of $1 \mathrm{~m}$ and a length of $30 \mathrm{~m}$; the effective length for measurements of dune morphology was $c a 17 \mathrm{~m}$. The slope of the flow could be varied, so it was possible to realize
Table 1. Result of sieve analysis of the used sediments.

\begin{tabular}{lllllll}
\hline Sand layer & & & & & & \\
$\quad$ Grain-size (mm) & $<0.35$ & 0.50 & 0.71 & $1 \cdot 00$ & $1 \cdot 4$ & $>1 \cdot 4$ \\
Fraction (-) & 0.000 & 0.05 & 0.20 & $0 \cdot 60$ & $0 \cdot 15$ & 0.00 \\
& & & & & & \\
Gravel layer & & & & & & \\
$\quad$ Grain-size (mm) & $<4.0$ & $5 \cdot 0$ & $8 \cdot 0$ & $11 \cdot 2$ & 16 & $>16$ \\
Fraction (-) & 0.001 & 0.01 & $0 \cdot 11$ & $0 \cdot 47$ & 0.39 & 0.02
\end{tabular}

The sand has a uniform distribution with a $d_{50}$ of $0.8 \mathrm{~mm}$. The table shows that the bulk of the sediment used for the gravel layer is between 8 and $16 \mathrm{~mm}$.

a uniform flow at the desired discharge and water depth.

A gravel layer was installed in the flume prior to the experiments. The gravel layer consisted of almost uniform gravel with $86 \%$ of the weight between 8 and $16 \mathrm{~mm}$ (Table 1). The grain-size of the gravel layer had been chosen such that it remained stable under the shear stresses observed in the experiments. The sediment which was transported over the coarse layer consisted of uniform quartz sand with a $d_{50}$ of $0 \cdot 8 \mathrm{~mm}$ (Fig. 2).

The experiments formed five series, each with a constant water depth and flow velocity (Table 2). During each experiment, the volume of sand remained constant because the sediment was recirculated. The sediment discharged at the downstream end of the flume was fed back to

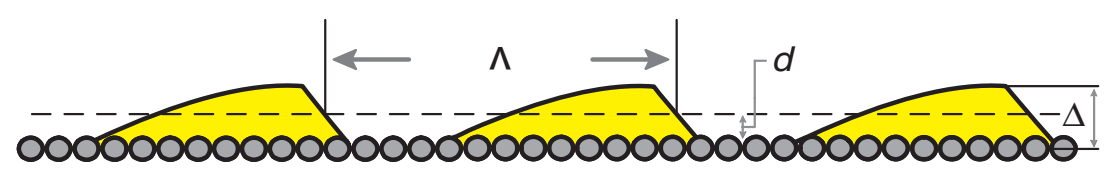

Fig. 2. Schematic illustration of the experimental conditions. Bedforms formed from mobile sand migrate over an immobile gravel layer. The dashed line indicates the average sand layer thickness $d$. The length between consecutive crossings of the lee side of the dune with the average height is the bedform length $\Lambda$. The height difference between the crest and the downstream trough is the bedform height $\Delta$. 
Table 2. Hydraulic conditions imposed in the different experimental series.

\begin{tabular}{lll}
\hline Series & $h(\mathrm{~m})$ & $u\left(\mathrm{~m} \mathrm{sec}^{-1}\right)$ \\
\hline 1 & $0 \cdot 20$ & $0 \cdot 52$ \\
2 & $0 \cdot 30$ & $0 \cdot 52$ \\
3 & $0 \cdot 15$ & $0 \cdot 52$ \\
4 & $0 \cdot 20$ & $0 \cdot 58-0 \cdot 67$ \\
5 & $0 \cdot 20$ & $0 \cdot 46$ \\
\hline
\end{tabular}

the upstream end of the flume. For each series, the volume of sand on the coarse layer increased with each experiment, thereby decreasing the supply limitation. The volume of sand - includ- ing pores - on the coarse layer is expressed per square metre as the average layer thickness $d$ (Table 3). It was determined by subtracting the measured level of the coarse layer from the measured level of the sand bed and averaging over the flume length and the equilibrium period.

The objective of the individual experiments was to take measurements of the bed morphology for each combination of layer thickness and flow conditions. It took some time before the conditions in the flume reached equilibrium after the start of an experiment. The bedform dimensions, sediment transport and bed roughness developed towards the equilibrium conditions. The slope of

Table 3. Overview of the key variables in the experiments: $d$ is the average layer thickness of transport layer, $Q$ is the water discharge, $h$ is water depth, $I_{\mathrm{e}}$ is energy slope, $\tau_{\mathrm{b}}$ is the bed shear stress, $C_{\mathrm{b}}$ is Chezy parameter related to the bed, $\Delta$ is the mean bedform height and $\sigma_{\Delta}$ the standard deviation of $\Delta, \Lambda$ is the bedform length and $\sigma_{\Lambda}$ is the standard deviation of $\Lambda$.

\begin{tabular}{|c|c|c|c|c|c|c|c|c|c|c|c|c|}
\hline Series & Exp & $t$ (day) & $d(\mathrm{~m})$ & $Q\left(1 \sec ^{-1}\right)$ & $h(\mathrm{~m})$ & $I_{\mathrm{e}}(\%)$ & $\tau_{\mathrm{b}}\left(\mathrm{N} \mathrm{m}^{-2}\right)$ & $C_{\mathrm{b}}\left(\mathrm{m}^{1 / 2} \mathrm{~s}^{-1}\right)$ & $\Delta(\mathrm{m})$ & $\sigma_{\Delta}(\mathrm{m})$ & $\Lambda(\mathrm{m})$ & $\sigma_{\Lambda}(\mathrm{m})$ \\
\hline 1 & 1 & 0.00 & 0.000 & $74 \cdot 3$ & $0 \cdot 20$ & -0.7 & $1 \cdot 25$ & $32 \cdot 9$ & 0 & 0 & 0 & 0 \\
\hline 1 & 2 & $1 \cdot 00$ & 0.003 & $103 \cdot 9$ & $0 \cdot 20$ & $-0 \cdot 8$ & $1 \cdot 33$ & $44 \cdot 7$ & 0.005 & 0.003 & $0 \cdot 23$ & $0 \cdot 14$ \\
\hline 1 & 3 & $0 \cdot 14$ & 0.003 & $104 \cdot 8$ & $0 \cdot 20$ & $-0 \cdot 8$ & $1 \cdot 38$ & $44 \cdot 0$ & $0 \cdot 006$ & $0 \cdot 002$ & $0 \cdot 21$ & $0 \cdot 13$ \\
\hline 1 & 4 & $0 \cdot 18$ & $0 \cdot 011$ & $104 \cdot 2$ & $0 \cdot 20$ & $-0 \cdot 8$ & $1 \cdot 48$ & $42 \cdot 4$ & 0.023 & 0.005 & $0 \cdot 63$ & $0 \cdot 11$ \\
\hline 1 & 5 & 0.05 & $0 \cdot 012$ & $106 \cdot 0$ & $0 \cdot 20$ & -0.9 & $1 \cdot 51$ & $42 \cdot 7$ & 0.023 & 0.005 & $0 \cdot 64$ & $0 \cdot 12$ \\
\hline 1 & 6 & $0 \cdot 32$ & 0.020 & $104 \cdot 5$ & $0 \cdot 20$ & $-1 \cdot 3$ & $2 \cdot 20$ & $35 \cdot 1$ & 0.039 & $0 \cdot 010$ & $0 \cdot 82$ & $0 \cdot 20$ \\
\hline 1 & 7 & $0 \cdot 71$ & 0.041 & $104 \cdot 3$ & $0 \cdot 20$ & $-1 \cdot 6$ & $2 \cdot 90$ & $30 \cdot 4$ & 0.055 & $0 \cdot 017$ & 1.06 & $0 \cdot 36$ \\
\hline 1 & 8 & $0 \cdot 73$ & 0.070 & $104 \cdot 3$ & $0 \cdot 20$ & $-1 \cdot 9$ & $3 \cdot 51$ & $28 \cdot 0$ & $0 \cdot 068$ & $0 \cdot 024$ & $1 \cdot 19$ & 0.48 \\
\hline 1 & 9 & 0.68 & 0.097 & $104 \cdot 4$ & $0 \cdot 20$ & $-1 \cdot 9$ & $3 \cdot 35$ & $29 \cdot 0$ & $0 \cdot 072$ & $0 \cdot 027$ & $1 \cdot 31$ & $0 \cdot 63$ \\
\hline 1 & 10 & $0 \cdot 89$ & $0 \cdot 161$ & $105 \cdot 3$ & $0 \cdot 20$ & $-2 \cdot 4$ & $4 \cdot 27$ & $25 \cdot 8$ & $0 \cdot 072$ & $0 \cdot 029$ & $1 \cdot 28$ & $0 \cdot 69$ \\
\hline 2 & 1 & $0 \cdot 00$ & 0.000 & $150 \cdot 6$ & $0 \cdot 30$ & $-0 \cdot 8$ & $2 \cdot 17$ & $33 \cdot 5$ & 0 & 0 & 0 & 0 \\
\hline 2 & 2 & $0 \cdot 26$ & 0.003 & $156 \cdot 3$ & $0 \cdot 30$ & $-0 \cdot 6$ & $1 \cdot 36$ & $44 \cdot 5$ & 0.006 & $0 \cdot 003$ & $0 \cdot 25$ & $0 \cdot 17$ \\
\hline 2 & 3 & $0 \cdot 24$ & $0 \cdot 011$ & $156 \cdot 8$ & $0 \cdot 30$ & $-0 \cdot 5$ & $1 \cdot 18$ & $48 \cdot 2$ & $0 \cdot 024$ & 0.006 & $0 \cdot 73$ & $0 \cdot 16$ \\
\hline 2 & 4 & 0.33 & $0 \cdot 019$ & $155 \cdot 6$ & 0.30 & $-0 \cdot 8$ & 1.93 & $37 \cdot 0$ & 0.041 & $0 \cdot 008$ & $0 \cdot 89$ & $0 \cdot 17$ \\
\hline 2 & 5 & $0 \cdot 36$ & 0.039 & $152 \cdot 6$ & $0 \cdot 30$ & -0.9 & $2 \cdot 18$ & $34 \cdot 3$ & $0 \cdot 064$ & $0 \cdot 015$ & $1 \cdot 21$ & $0 \cdot 26$ \\
\hline 2 & 6 & 0.59 & 0.067 & $157 \cdot 1$ & 0.29 & $-1 \cdot 2$ & 3.00 & $30 \cdot 7$ & 0.078 & $0 \cdot 024$ & $1 \cdot 27$ & 0.43 \\
\hline 2 & 7 & 0.95 & 0.095 & $157 \cdot 2$ & $0 \cdot 30$ & $-1 \cdot 0$ & $2 \cdot 47$ & $33 \cdot 2$ & $0 \cdot 082$ & $0 \cdot 028$ & 1.51 & $0 \cdot 61$ \\
\hline 3 & 1 & $0 \cdot 14$ & $0 \cdot 004$ & $78 \cdot 7$ & $0 \cdot 15$ & $-1 \cdot 3$ & $1 \cdot 74$ & $39 \cdot 7$ & $0 \cdot 007$ & 0.004 & $0 \cdot 25$ & $0 \cdot 14$ \\
\hline 3 & 2 & $0 \cdot 47$ & 0.011 & $79 \cdot 0$ & $0 \cdot 15$ & $-1 \cdot 2$ & 1.63 & $41 \cdot 0$ & 0.021 & $0 \cdot 006$ & 0.62 & $0 \cdot 16$ \\
\hline 3 & 3 & $0 \cdot 12$ & $0 \cdot 021$ & $76 \cdot 8$ & $0 \cdot 15$ & $-1 \cdot 5$ & $2 \cdot 02$ & $36 \cdot 0$ & 0.034 & 0.009 & $0 \cdot 81$ & $0 \cdot 22$ \\
\hline 3 & 4 & 0.95 & 0.037 & $77 \cdot 8$ & $0 \cdot 16$ & $-1 \cdot 5$ & $2 \cdot 12$ & $34 \cdot 2$ & 0.046 & $0 \cdot 015$ & 0.98 & $0 \cdot 38$ \\
\hline 3 & 5 & $0 \cdot 30$ & 0.067 & $78 \cdot 5$ & $0 \cdot 15$ & $-2 \cdot 0$ & $2 \cdot 80$ & $30 \cdot 5$ & $0 \cdot 056$ & $0 \cdot 019$ & $1 \cdot 12$ & 0.52 \\
\hline 3 & 6 & $0 \cdot 86$ & $0 \cdot 160$ & $80 \cdot 2$ & $0 \cdot 15$ & $-2 \cdot 8$ & 3.94 & $26 \cdot 2$ & 0.062 & $0 \cdot 026$ & $1 \cdot 20$ & 0.63 \\
\hline 4 & 1 & $0 \cdot 11$ & 0.003 & $134 \cdot 7$ & $0 \cdot 20$ & $-1 \cdot 2$ & $2 \cdot 07$ & $46 \cdot 4$ & $0 \cdot 006$ & 0.003 & $0 \cdot 22$ & $0 \cdot 13$ \\
\hline 4 & 2 & $0 \cdot 12$ & $0 \cdot 012$ & $135 \cdot 1$ & $0 \cdot 20$ & $-1 \cdot 8$ & $3 \cdot 12$ & $37 \cdot 8$ & $0 \cdot 028$ & $0 \cdot 008$ & $0 \cdot 68$ & $0 \cdot 19$ \\
\hline 4 & 3 & $0 \cdot 17$ & 0.021 & $116 \cdot 0$ & $0 \cdot 20$ & $-1 \cdot 6$ & $2 \cdot 94$ & $33 \cdot 6$ & 0.041 & $0 \cdot 011$ & $0 \cdot 84$ & 0.25 \\
\hline 4 & 4 & $0 \cdot 91$ & 0.039 & $116 \cdot 3$ & $0 \cdot 20$ & $-2 \cdot 2$ & $4 \cdot 07$ & $28 \cdot 5$ & $0 \cdot 058$ & $0 \cdot 016$ & 0.99 & $0 \cdot 29$ \\
\hline 5 & 1 & 0.05 & 0.003 & $93 \cdot 2$ & $0 \cdot 20$ & $-0 \cdot 6$ & $1 \cdot 05$ & $45 \cdot 4$ & 0.005 & $0 \cdot 002$ & $0 \cdot 24$ & $0 \cdot 18$ \\
\hline 5 & 2 & $0 \cdot 10$ & 0.004 & $93 \cdot 1$ & $0 \cdot 20$ & $-0 \cdot 7$ & $1 \cdot 13$ & $43 \cdot 5$ & 0.006 & 0.003 & $0 \cdot 26$ & $0 \cdot 19$ \\
\hline 5 & 3 & $0 \cdot 24$ & 0.009 & $91 \cdot 5$ & $0 \cdot 20$ & $-0 \cdot 7$ & $1 \cdot 12$ & $42 \cdot 7$ & $0 \cdot 016$ & 0.005 & $0 \cdot 75$ & $0 \cdot 17$ \\
\hline 5 & 4 & $0 \cdot 50$ & 0.019 & $92 \cdot 9$ & $0 \cdot 20$ & $-0 \cdot 7$ & $1 \cdot 23$ & $41 \cdot 9$ & 0.033 & $0 \cdot 008$ & 0.94 & $0 \cdot 21$ \\
\hline 5 & 5 & $0 \cdot 39$ & 0.038 & $92 \cdot 5$ & $0 \cdot 20$ & -0.9 & 1.51 & $37 \cdot 5$ & 0.051 & $0 \cdot 015$ & $1 \cdot 15$ & 0.33 \\
\hline 5 & 6 & 0.92 & 0.065 & $93 \cdot 0$ & $0 \cdot 20$ & $-1 \cdot 2$ & $2 \cdot 09$ & $31 \cdot 8$ & 0.064 & $0 \cdot 021$ & $1 \cdot 27$ & 0.52 \\
\hline 5 & 7 & $0 \cdot 81$ & $0 \cdot 159$ & $93 \cdot 7$ & $0 \cdot 20$ & $-1 \cdot 5$ & $2 \cdot 74$ & $27 \cdot 4$ & 0.065 & 0.023 & $1 \cdot 25$ & $0 \cdot 46$ \\
\hline 5 & 8 & $1 \cdot 47$ & $0 \cdot 160$ & $93 \cdot 7$ & $0 \cdot 20$ & $-1 \cdot 7$ & $3 \cdot 13$ & $26 \cdot 8$ & $0 \cdot 066$ & 0.025 & $1 \cdot 27$ & 0.57 \\
\hline 5 & 9 & $0 \cdot 65$ & $0 \cdot 159$ & $93 \cdot 7$ & $0 \cdot 20$ & $-1 \cdot 5$ & $2 \cdot 68$ & $27 \cdot 9$ & 0.061 & $0 \cdot 022$ & $1 \cdot 15$ & $0 \cdot 42$ \\
\hline
\end{tabular}


the bed and the level of the downstream weir were adjusted regularly to maintain uniform flow conditions at the desired water level during this adaptation period. The experiment was continued without further adjustment once the conditions were varying around a mean and thus was in equilibrium. Under supply-limited conditions, less variation in the conditions was observed over time than was the case under alluvial conditions. Therefore, the experiments were continued for a few hours after an equilibrium had been reached under supply limited conditions, while the observations were continued for up to two days under alluvial conditions (Table 3). The measurements from the equilibrium periods were used for the analysis of the bedform characteristics.

Measurements were made using an automated carriage that measured the bed and water level during the experiments over a length of $17.5 \mathrm{~m}$ with ultrasound sensors. The water level was measured approximately in the centre of the flow. The bed level was measured at three parallel transects; at $y=0.165,0.500$ and $0.835 \mathrm{~m}$, where $y=0$ is the left side wall when looking downstream. The accuracy of the bed-level measurements was tested by repeatedly measuring a fixed profile. The vertical standard deviation is $<1 \mathrm{~mm}$, while the horizontal standard deviation is ca $3 \mathrm{~mm}$. In the horizontal direction, the accuracy is limited by the area of the measurement surface. The radius of the measurement surface was a few centimetres. Therefore, the ultrasound measurements are suitable for measuring the large-scale features of the dunes, but the grain scale cannot be resolved. The accuracy of the sensor for the water level is comparable to that of the bed-level sensors. The carriage measured the bed and water levels continuously. It took about $3 \mathrm{~min}$ to take a measurements profile in one direction, after which the carriage immediately started measuring in the opposite direction.

After Series 1 experiments, a detailed scan of the bed morphology was made using a laser distance measurement instrument. This sensor has a measurement area of $0 \cdot 2 \times 4 \mathrm{~mm}$ and can therefore be used to make bed-level measurements with a higher spatial resolution. In the scans made with this instrument, the bed level was measured every $1 \mathrm{~mm}$ in the $\mathrm{x}$-direction, along the flume, and every $4 \mathrm{~mm}$ in the lateral $y$-direction. The standard deviation in the $y$-direction and the $z$-direction, normal to the flume bottom, of these measurements is $<1 \mathrm{~mm}$. The positioning of the sensor in $x$-direction is slightly less accurate with a standard deviation of $<2 \mathrm{~mm}$.
The discharge from the large water recirculation system and the smaller sediment recirculation system was measured using inductive measurement devices. The accuracy of these instruments is $\mathrm{Ca} 1 \%$ according to their specifications. From these measurements, the average flow velocity was calculated by dividing the total discharge by the water depth and flume width. Subsequently, the total shear stress was calculated from the gradient in the energy level, assuming equilibrium flow. The total shear stress was divided in a wall and bed-related part using the method of Vanoni \& Brooks (1957). The bed shear stress $\left[\tau_{\mathrm{b}}\left(\mathrm{N} \mathrm{m}^{-2}\right)\right]$ is reported in Table 3 .

\section{EXPERIMENTAL RESULTS}

\section{Bed-level observations}

Between the experiments, the layer thickness was increased and therefore the bedform characteristics changed. This effect is illustrated firstly with pictures from the three-dimensional laser surface scans and examples of bed-level profiles from Series 1. Figure 3 shows a height map of a section of $5 \mathrm{~m}$ from the laser surface scans. The patterns are clearly visible in this figure, but the height is not. Therefore, Fig. 4 shows the longitudinal bedlevel profiles of the centre bed-level sensor. A histogram of the observed bed-level elevations is shown next to the profiles in Fig. 4. This figure shows how often a certain level was observed. The profiles are just examples as a new profile was made every $3 \mathrm{~min}$. The distribution shows the observed levels in all profiles over the equilibrium period.

In Fig. 3, Exp. 1-1, a scan of the gravel layer is shown. There was no sediment movement that could create bedforms as the gravel was immobile. In Exp. 1-3, a sand layer of $1 \mathrm{~cm}$ in depth had been distributed over the coarse layer. A part of this sand disappeared from the active layer because it fell into the coarse layer. Another part of the sand laid at the surface but between the gravel particles. This part could not contribute to an increase in average bed level, because the relatively large measurement area of the echo sensor could not detect it. Therefore, a few millimetres of sand ( \pm 2 to $5 \mathrm{~mm}$ ) is not included in the thickness of the sand layer $d$, as reported in Table 3. The morphological pattern that emerged in the sand layer during the experiment is visible in Fig. 3, Exp. 1-3. Two flow parallel stripes formed where the sand transport concentrated. 

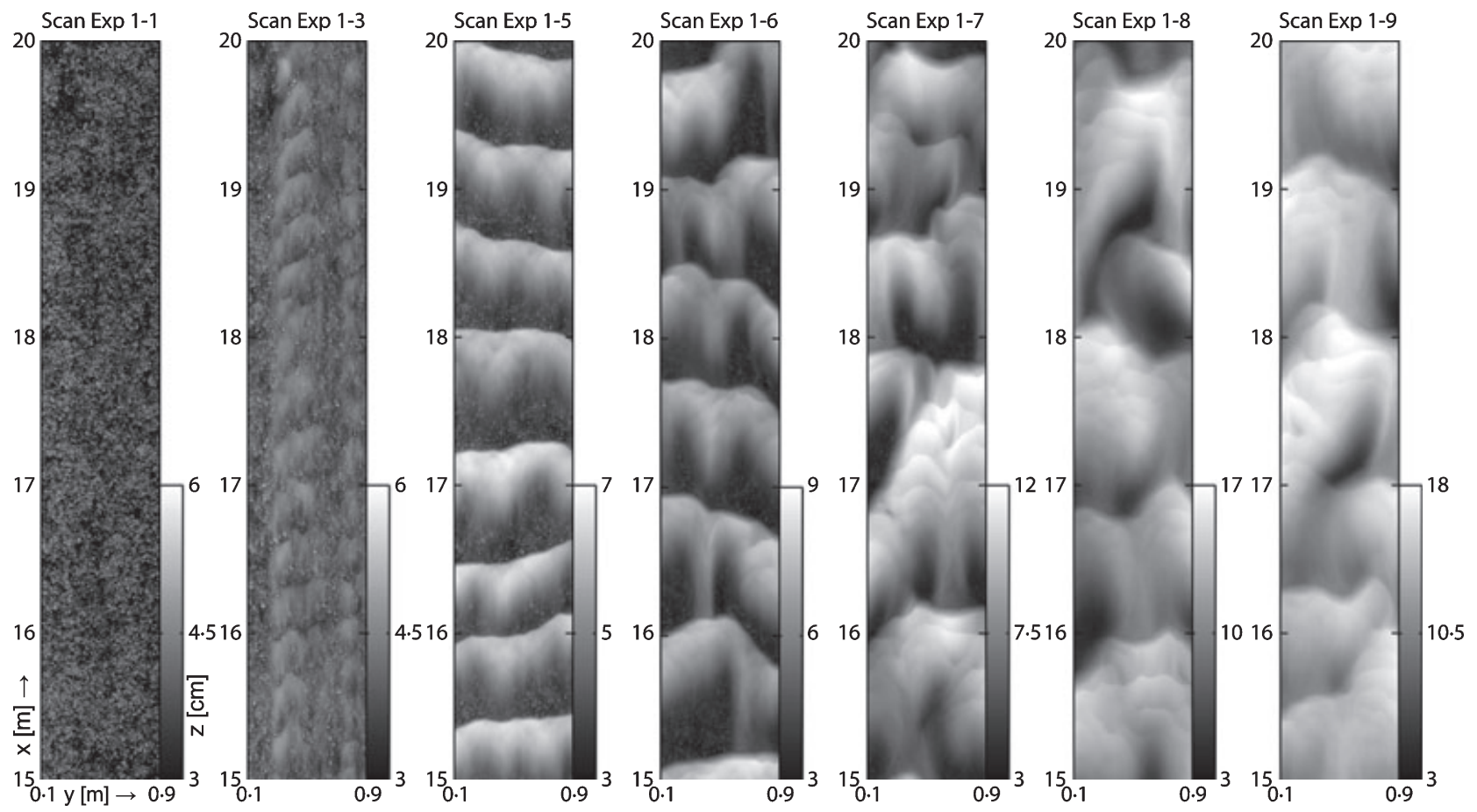

Fig. 3. Laser surface scans from the situation after the experiments of Series 1 . The level of grey indicates the height. The mean bed level is grey. The flume sidewalls are located at 0 and $1 \mathrm{~m}$, so $10 \mathrm{~cm}$ is missing on both sides. Flow is from bottom to top.

Ripple-like bedforms are present in the stripes. No profiles are shown for this experiment in Fig. 4 because the relief is very low; the sandy bedforms formed between the gravel particles. In Exps 1-4 and 1-5, which had the same flow conditions, the sand layer thickness has been increased again by $1 \mathrm{~cm}$. The effective layer thickness is now $12 \mathrm{~mm}$. In these experiments, straight-crested dunes appeared with a very regular topography. When more sand was added, the bedforms grew bigger and became more irregular. This effect is illustrated in Figs 3 and 4 by the disappearance of the straight crests, the appearance of the overlapping of dunes and the development of secondary bedforms on top of the larger dunes. With a further increasing sand layer thickness, the influence of the coarse layer vanished.

In Fig. 4, Exps 1-4 and 1-6, the coarse layer is exposed between almost every dune. Therefore, all sand in the flume is part of a dune. No sand layer remains immobile while dunes are migrating over it, apart from the small amount of sand trapped in the pockets of the gravel layer. In Exp. 1-7, it can be seen that the troughs of the dunes often are not on the coarse layer. A lag-deposit of sand is present under the dunes. Some troughs are deeper and reach the coarse layer. So the sediment in the lag-deposit is regularly entrained in the transport process. In Exp. 1-8, this lag-deposit has developed further. No troughs any longer reach the coarse layer in the profile shown here. In the histogram, it can be seen that the coarse layer still is exposed sometimes, though the histogram shows a peak at the level of the coarse layer. In Exp. 1-9, the lag deposit has developed further and the troughs reach the coarse layer for only $<1 \%$ of the dunes. Therefore, the influence of the supply limitation disappears in Exp. 1-9 and the dune dimensions are not significantly different from the dune dimensions of the alluvial reference experiment for Series 1, Exp. 1-10.

So, for a small sediment supply no lag deposits are observed. At some point, dunes start to coalesce and a lag-deposit starts to develop. This lag-deposit grows with the increasing sediment supply until the troughs no longer reach the coarse layer. At that point, the dunes are no longer supply-limited.

In the other series (Series 2 to 5), the same experiments were performed at water depths and flow velocities different from those in Series 1. In these series, similar trends were observed as will be shown in the following sections where the 

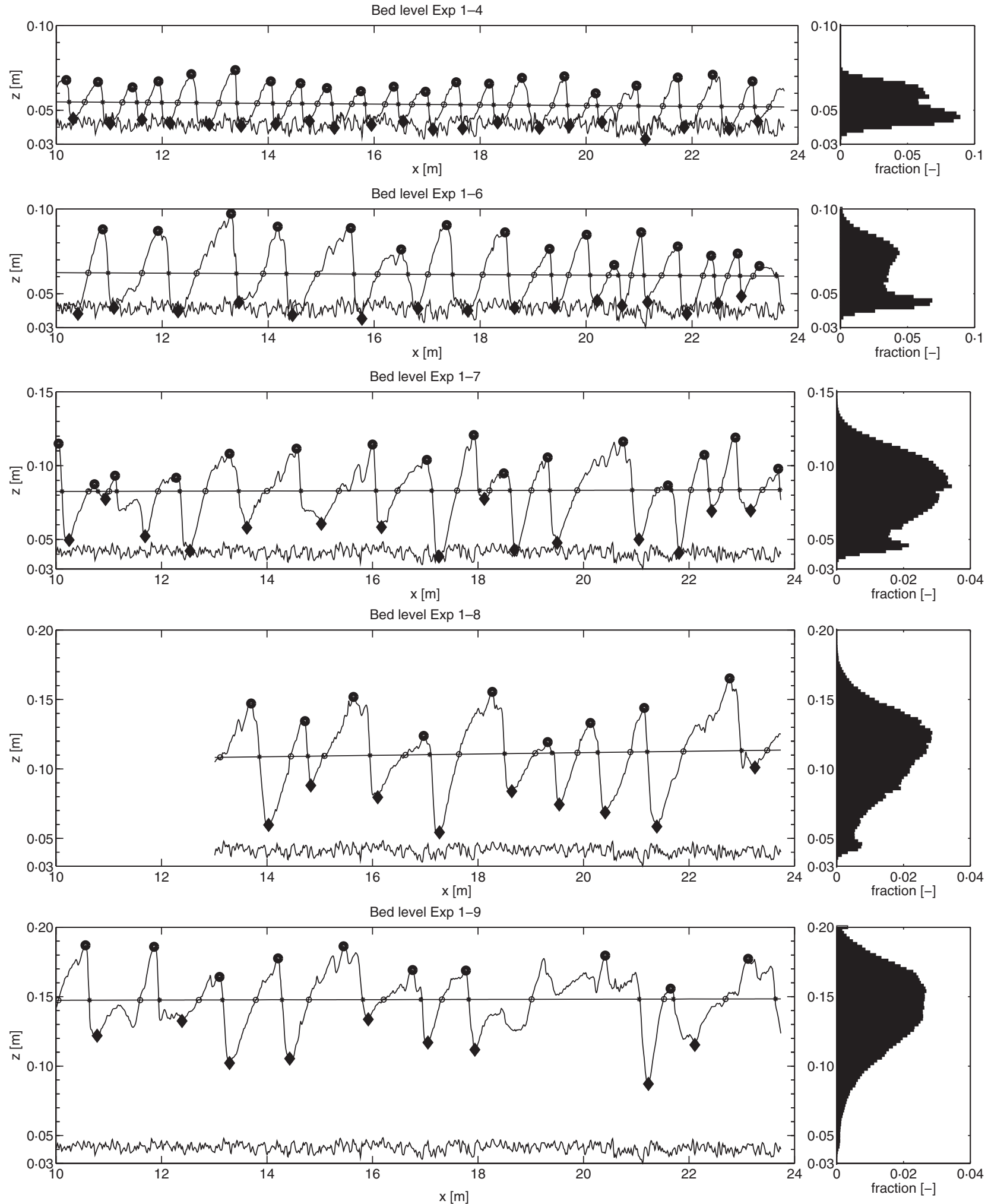

Fig. 4. Bed-level profiles from the centre bed-level sensor. The irregular line at the bottom of each figure is a scan of the gravel layer. The straight line through the dunes is a linear fit line, the zero-level for the zero-crossing bedformrecognition routine. The circles and stars on the line show the zero-crossings, the diamonds and the circles mark the location of the crests and troughs as located by the zero-crossing routine. The rotated histograms at the right of the profiles show the distributions of the observed bed levels. 
relationship of the bedform dimensions with thickness of the sand layer is explored.

\section{Method of determining the bedform dimensions}

Bedform dimensions were determined from the measured bed-level profiles using a 'zero-crossing' method (Van der Mark et al., 2008). In this method, the crossings of the bed level with a fitted linear trend line are recognized (Fig. 2). Between an up and a down crossing, a crest is selected at the maximum, and between a down and an up crossing, a trough is selected at the minimum. The bedform length $[\Lambda(\mathrm{m})]$ is defined as the distance between successive down crossings. The bedform height $[\Delta(\mathrm{m})]$ is defined as the height difference between a crest and the trough on the downstream side.

Using this method, secondary bedforms smaller bedforms migrating on top of other bedforms - are sometimes recognized. In other studies, such secondary bedforms were often removed because the researchers were only interested in dune dimensions and bedforms smaller than a certain size were not considered to be dunes (e.g. Bakker, 1982; Allen, 1984; Leclair, 2002). In the present study, no minimum length or height for a dune has been defined because the bedforms vary in size due to the supply limitation. The bedforms that are considered here to be supply-limited dunes in one case have the same dimensions as the secondary bedforms in another experiment. Therefore, a different threshold would have to be used for every experiment, making the analysis subjective. The total distribution of observed dune dimensions is analysed here. The effect of not removing secondary bedforms is that the reported dimensions will be somewhat smaller. This effect is small because the secondary bedforms form on the crests of dunes, usually above the mean level of the bed, which is used for bedform detection.

\section{Variation in average dune dimensions with supply limitation}

The bedform dimensions were determined for all profiles within the equilibrium period ( 25 to 700 profiles) of each experiment using the method explained above. The average and the standard deviation of the height and length are shown in Figs 5 and 6. It can be seen that the average dune dimensions increase with an increasing (sand) layer thickness for all series of experiments. In
Figs $5 \mathrm{~A}$ and $6 \mathrm{~A}$, the flow velocity is equal for all series $\left(u=0.52 \mathrm{~m} \mathrm{sec}^{-1}\right)$ and the water depth varies between the series. It can be seen that, for increasing water depths, the dunes grow to larger dimensions under alluvial conditions. The differences in average dune dimensions between the series decreases with a decreasing sediment availability.

Figures $5 \mathrm{~B}$ and $6 \mathrm{~B}$ show the increase in dune height and length with an increase in $d$ for series with a constant water depth; now the flow velocity was varied between these series. The bedforms grow towards larger dimensions for Series $1 \quad\left(u=0.52 \mathrm{~m} \mathrm{sec}^{-1}\right)$ than for Series 5 $\left(u=0.46 \mathrm{~m} \mathrm{sec}^{-1}\right)$. Series 4 seems to grow towards an alluvial height, which is equal to Series 1; unfortunately observations for a layer thickness larger than $4 \mathrm{~cm}$ were not available to the authors.

The bars in Fig. 5 show the range of one standard deviation in bedform height. The standard deviation $(\sigma)$ increases with $d$. The relative standard deviation, the standard deviation divided by the average $(\mu)$, also increases with increasing sediment supply (Fig. 7). This observation shows that the supply-limited dunes are more regular than the alluvial dunes. The increase in relative standard deviation for $d \rightarrow 0$ is caused by coarse grains, which are recognized as bedforms. These points can be ignored.

The dune height divided by the length, namely the dune steepness, is shown in Fig. 8. The steepness increases quickly with increasing sediment availability. The alluvial steepness was reached at a layer thickness of $c a 5 \mathrm{~cm}$, whereas the length and the height of the dunes was still increasing, as can be seen in Figs 5 and 6; this suggests that the dune steepness is constant in the slightly supply-limited regime. The height approaches zero for a strong supply limitation, while the length does not. See the surface scan of Exp. 1-3 in Fig. 3: the wavelength is still clearly recognizable while the height of the bedforms is so small that the coarse layer is just covered at the crests of the dunes.

\section{Spectral development from supply-limited to alluvial conditions}

A spectrum of the bed-level profiles can reveal whether dominant wavelengths are present or whether the bed consists of many different wavelengths. It has been shown that longitudinal wave number spectra show a -3 slope over a certain range for fully developed sand wave fields (Nordin \& Algert, 1966; Hino, 1968; Nikora et al., 

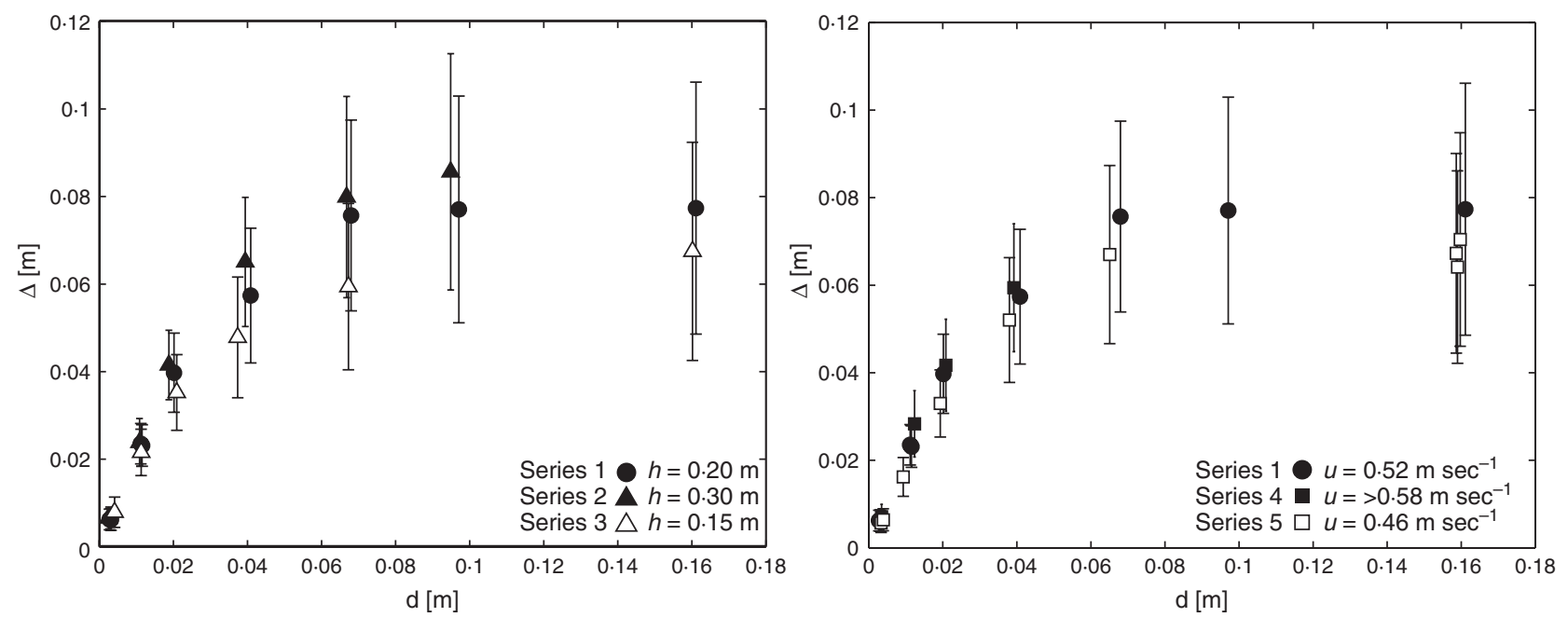

Fig. 5. (A) Left and (B) right. The average dune height versus the average layer thickness. The bars indicate the standard deviation of the observations.
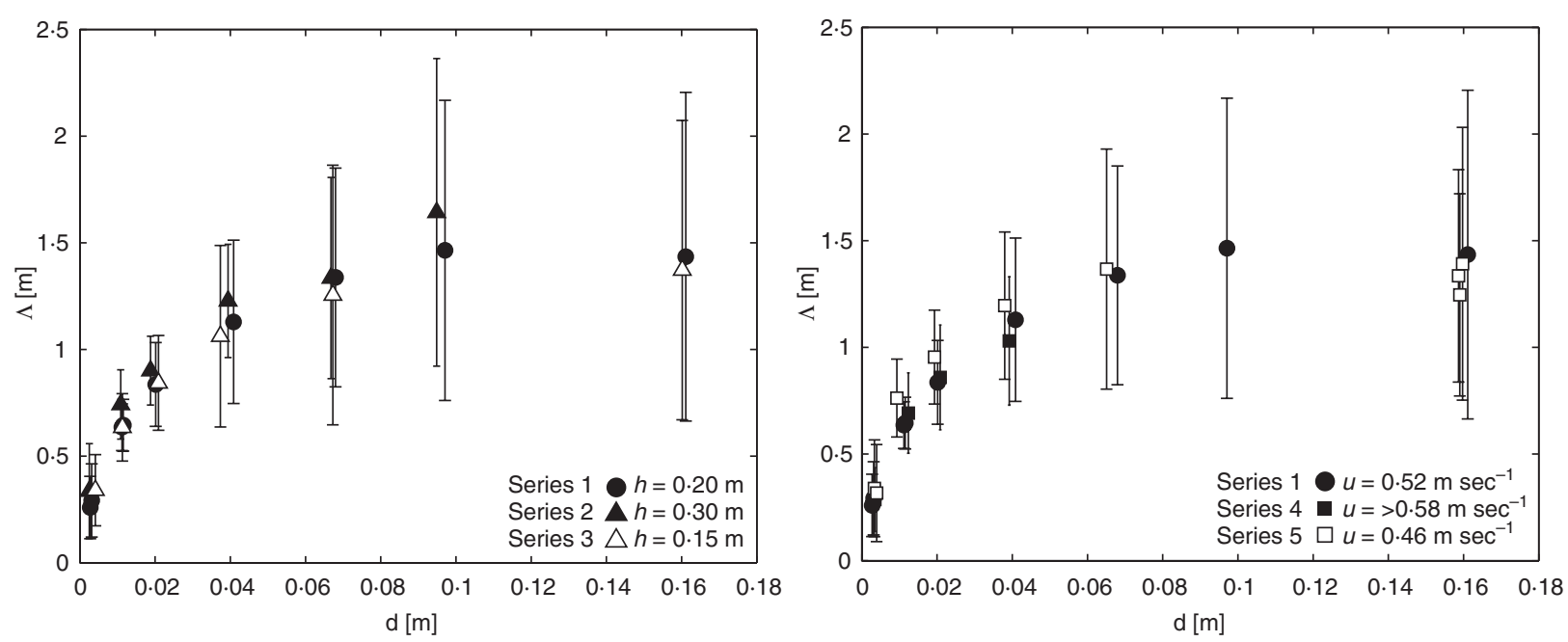

Fig. 6. (A) Left and (B) right. The average dune length versus the average layer thickness. The bars indicate the standard deviation of the observations.
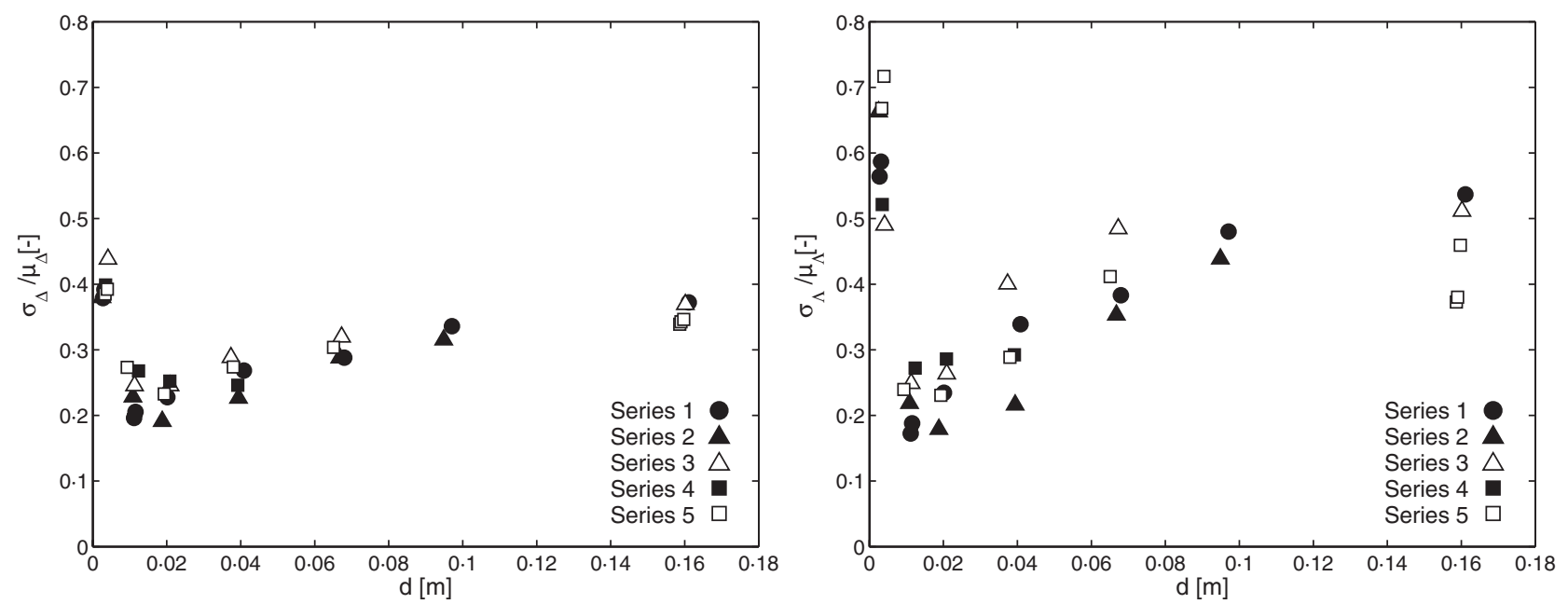

Fig. 7. (A) Left and (B) right. The relative standard deviation of the height (A) and length (B) versus the average layer thickness.

ㄷ 2009 The Authors. Journal compilation ㄷ 2009 International Association of Sedimentologists, Sedimentology, 56, 1713-1727 

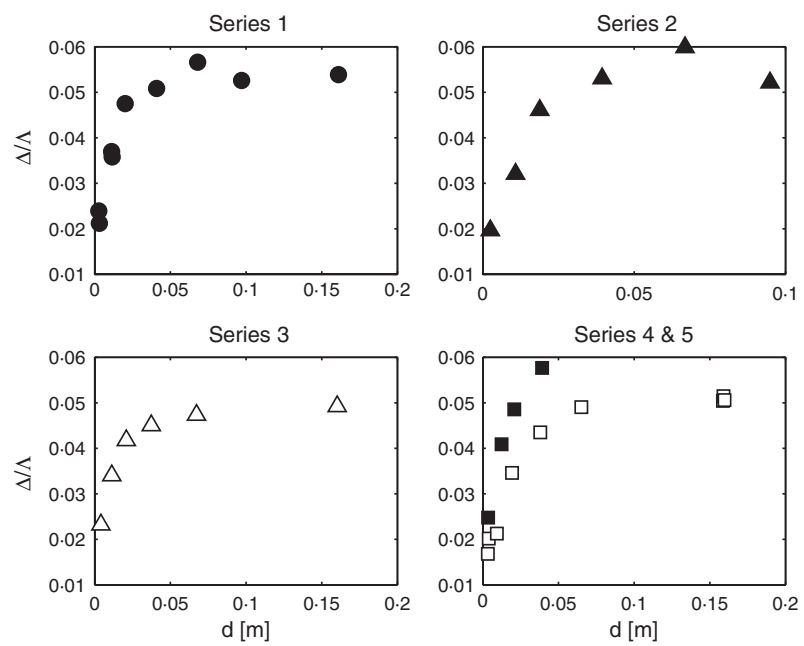

Fig. 8. The bedform steepness, $\Delta / \Lambda$, for the different series. The symbols are the same as in Fig. 7 .

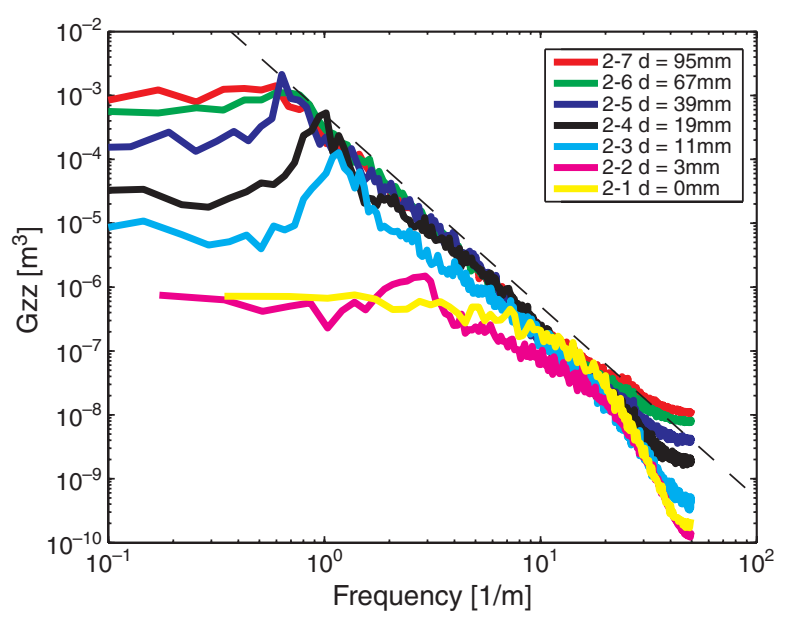

Fig. 9. The spectra for the experiments of Series 2 .

1997). This means that, in a sand wave field, all wavelengths are present between a certain minimum and maximum wavelength, these wavelengths are controlled by the bed shear stress and the sediment characteristics. This range of wavelengths is called the scaling region (Nikora et al., 1997).

Figure 9 shows the longitudinal wave number spectra for the experiments of Series 2. The -3 scaling law is indicated by the straight dashed line. Going from supply-limited to alluvial conditions, a development towards this -3 slope is visible in the presented experiments. In the spectrum of the coarse bed (Exp. 2-1), the -3 slope - and thus a scaling region - is not visible and no spectral peaks are present. Adding a sand layer of $1 \mathrm{~cm}$ in Exp. 2-2 causes the loss of energy between a wavelength of 3 and $30 \mathrm{~cm}$ and causes a small peak at a wavelength between 30 and $50 \mathrm{~cm}$; this shows that the sand smoothes out the small imperfections in the handmade bed. The small spectral peak reveals the presence of small bedforms. These are bedforms comparable to Fig. 3, Exp. 1-3, which are extremely supplylimited dunes. The bedform length related to this peak agrees with the mean bedform length measured with the zero-crossing method as reported in Table 3 and Fig. 6A.

With further increasing sediment availability, the peak in the spectrum shifts towards lower frequencies and the total variance (the area under the spectrum) increases. Gradually, the spectrum to the right of the peak starts to approach the -3 slope; this indicates an increasing spectral energy for wavelengths smaller than the peak wavelength. This effect can be attributed to the increasing presence of small bedforms superimposed on the larger ones. When the alluvial situation is approached (see Exps 2-6 and 2-7), the well-defined peak disappears and the energy in the spectrum spreads over a wide range of frequencies. This observation agrees with the increasing standard deviation of bedform lengths and heights shown in Figs 5 and 6. With an increase in the sediment availability, not only do the bedform dimensions increase, but also the bedforms become more irregular.

\section{Comparison of the results from the spectral and zero-crossing method}

Both zero-crossing and spectral analyses provide different information on the bedform characteristics. An extensive treatment of the relationship between dune dimensions from a zero-crossing method and the statistical properties of bed-level profiles is given in Nordin (1971).

The peak wavelength - as can be observed in the spectra - provides an alternative means to characterize the bedform length. In Fig. 10, the peak wavelength, $\Lambda$-peak, is compared to the mean wavelength from the zero-crossing method. The results from both methods are very similar up to a $\Lambda$-mean of $c a 1.2 \mathrm{~m}$. Figure 10 shows that the observations follow the $\Lambda$-mean $=\Lambda$-peak relationship, with a small systematic difference between the two methods. Up to the wavelength of $\pm 1.2 \mathrm{~m}$, the dunes are regular and their spectra are peaked. From this point on the spectra are no longer peaked, instead they tend to show an approximately equal spectral energy for all longer wavelengths. See the horizontal lines for Exps 2-6 and 2-7 in Fig. 9 for wavelengths $>1.4 \mathrm{~m}$. Under 


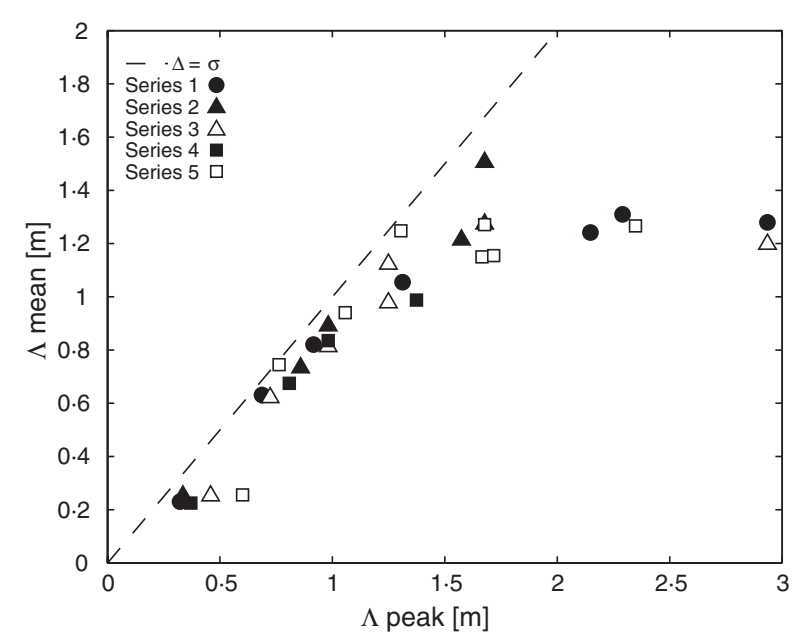

Fig. 10. The mean bedform length versus the peak wavelength from the spectra.

these alluvial conditions, wavelengths longer than $\Lambda$-mean sometimes have a slightly larger spectral energy, which causes a difference between the $\Lambda$-mean and $\Lambda$-peak. These peaks do not represent actual dune wavelengths, as the amplitude is very small compared to the wavelength. It suggests the presence of larger bed features (Nikora et al., 1997). It has been suggested that the characteristic wavelength in this case is the wavelength of the end of the scaling region.

Unlike the bedform length, the bedform height cannot be directly read from the spectrum. However, the area under the spectrum the total variance of the bed - is related to the bedform height. It has been shown that $\Delta / 2$ is distributed according to a Rayleigh distribution (Cartwright \& Longuet-Higgins, 1956 in Nordin, 1971) if the bed elevations have a Gaussian distribution with standard deviation $\sigma$. This can be expressed as:

$$
p\left(\frac{\Delta}{2}\right)=\frac{\Delta}{\sigma} \mathrm{e}^{-\left(\frac{\Delta}{2 \sqrt{\sigma}}\right)^{2}}
$$

The bedform dimensions from the zero-crossing method reported here are averages. The mean bedform height $\left(\mu_{\Delta}\right)$ can then be calculated as follows (Bendat \& Piersol, 2000):

$$
\mu_{\Delta}=2 \sigma \sqrt{\frac{\pi}{2}} \approx 2 \cdot 5 \sigma
$$

The mean bedform height is therefore $\mathrm{ca} 2 \cdot 5$ times the standard deviation of the bed level. Figure 11

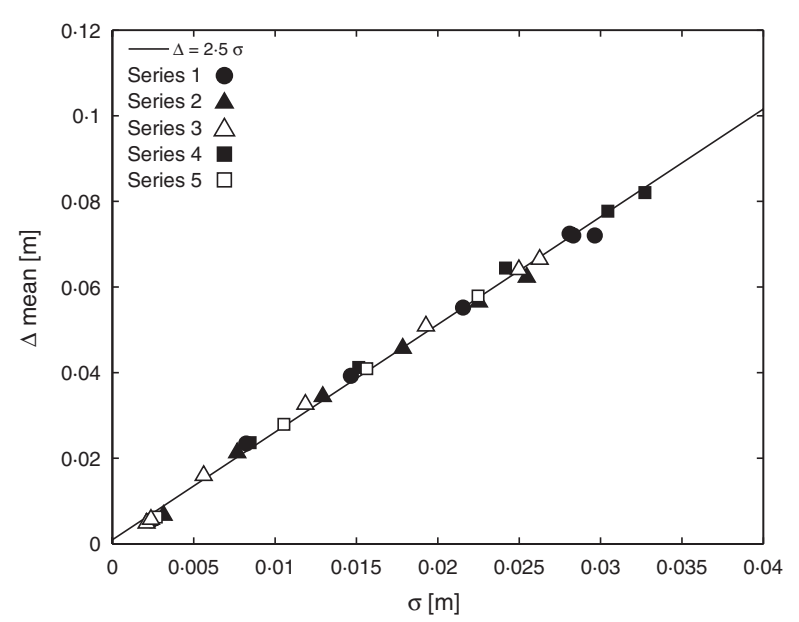

Fig. 11. Mean bedform height versus the standard deviation from the bed level.

shows the bedform height from the zero-crossing method against the standard deviation, the square root of the variance. The data points lie on a straight line with a steepness of $2 \cdot 5$. This agrees with the result of Cartwright \& Longuet-Higgins (1956), even though the bed-level distribution is not Gaussian in all experiments due to the presence of the coarse layer, see Fig. 4.

\section{EMPIRICAL RELATIONSHIP BETWEEN DUNE DIMENSIONS AND SUPPLY LIMITATION}

A relationship between the dune height and the sand layer thickness may be useful when predicting the bed roughness and sediment transport for supply-limited situations. Therefore, the experimental data were used to derive an empirical model.

Figure 12 shows that the steepness of the fitted functions decreases with a decreasing distance to the asymptotic value, the alluvial dune height $\left(\Delta_{0}\right)$ :

$$
\frac{\mathrm{d} \Delta}{\mathrm{d}(d)} \sim-\left(\Delta-\Delta_{0}\right)
$$

$L$ is introduced as a characteristic length parameter to fit the model:

$$
L \frac{\mathrm{d} \Delta}{\mathrm{d}(d)}=\Delta_{0}-\Delta
$$

Integration of this equation gives:

$$
\frac{\Delta}{\Delta_{0}}=1-\exp \left(-\frac{d}{L}+C\right)
$$



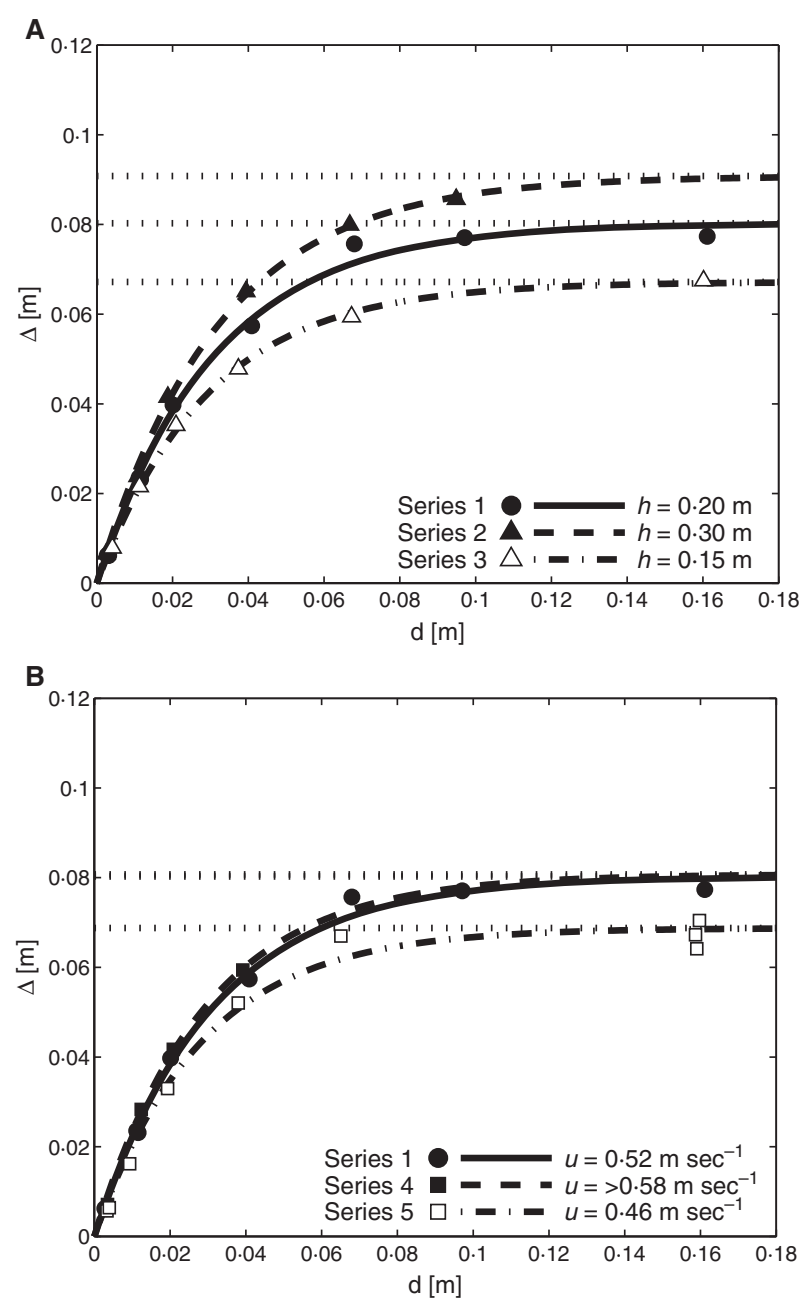

Fig. 12. (A) Top and (B) bottom. Dune height observations with fitted trend lines. The equation behind the trend line is Eq. 5. The fits have been used to determine the asymptotic values of the dune height, which is considered to be the alluvial dune height $\left(\Delta_{0}\right)$.

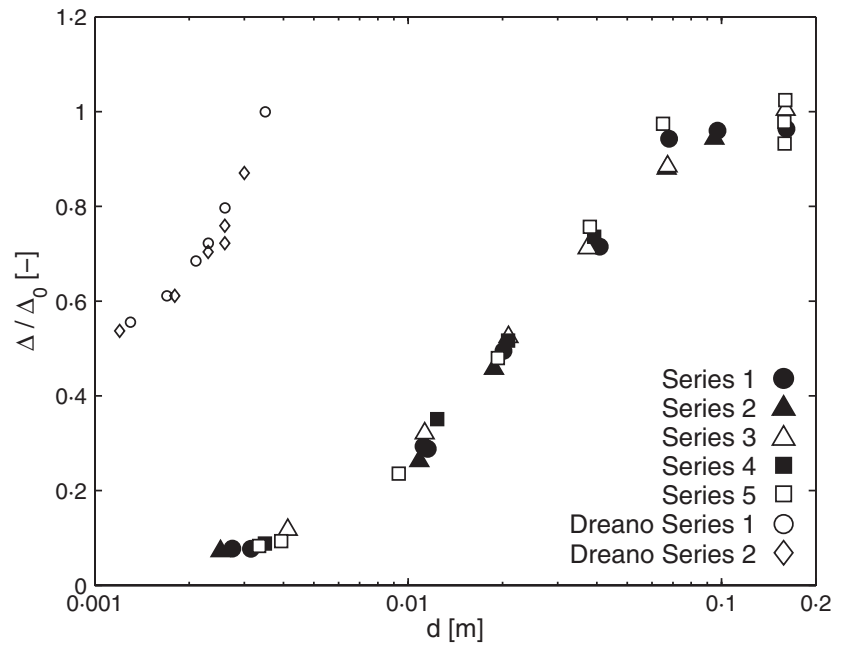

The integration constant, $C$, is zero because $\Delta=0$ for $d=0$. If $L$ is a constant, Eq. 5 suggests that there should be one relationship between the relative dune height $\left(\Delta / \Delta_{0}\right)$ and the layer thickness $d$. Figure 13 shows the relative dune height against the layer thickness. It indeed shows that the measured dune heights collapse to one line when the dune height is divided by the alluvial dune height $\Delta_{0}$. The dune length also shows this collapse when divided by the dune length under alluvial conditions but the scatter is larger. Unfortunately, the absolute value of $d$ cannot be considered a good model parameter. If applied to a situation where the water depth and dune size are much smaller or larger, then the absolute $d$ from these experiments will have no predictive power. It can be assumed that the parameter $L$ is related to $\Delta_{0}$, but the variation in $\Delta_{0}$ in these experiments is too small to demonstrate the relationship. Another set of experimental data from Dreano et al. (2008) is used for this purpose. These data have also been plotted in Fig. 13 and are visible to the left of the data for the present study.

Several key characteristics of the experiments by Dreano et al. (2008) are mentioned here; their experiments are comparable to the experiments presented here because the supply limitation was also systematically varied while measuring the bedform characteristics. However, the scale of the experiments by Dreano et al. is much smaller; therefore, they can provide additional information. The water depth, in a closed duct flume, was $3.5 \mathrm{~cm}$ compared to 20 to $30 \mathrm{~cm}$ in the present experiments. In the experiments, glass beads $-0.1 \mathrm{~mm}$ in diameter with a density of

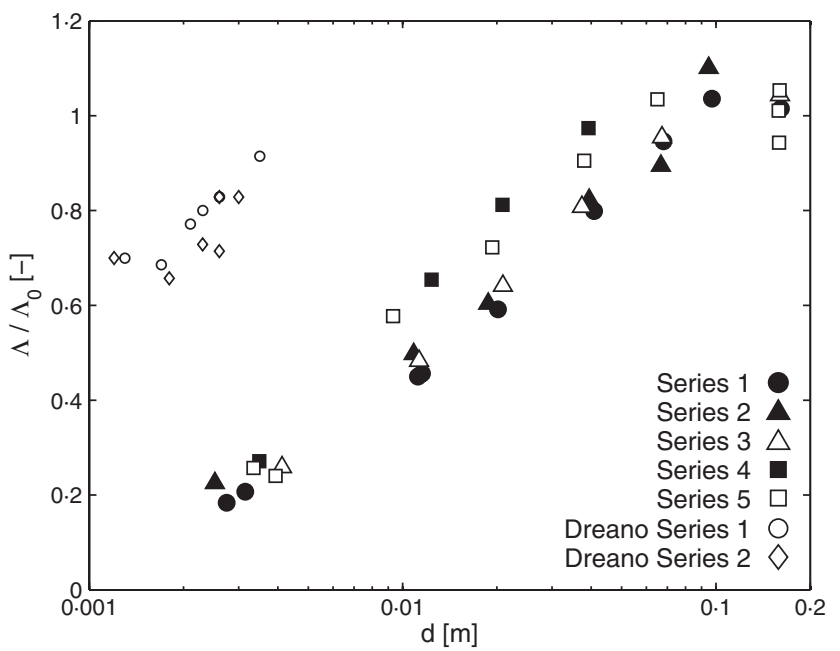

Fig. 13. (A) Left and (B) right. Relative dune height $\left(\Delta / \Delta_{0}\right)$ and relative dune length $\left(\Lambda / \Lambda_{0}\right)$ versus the layer thickness, on a logarithmic axis. 
$2.5 \mathrm{~g} \mathrm{~cm}^{-3}$ - were fed into a flume and transported over a surface with glass beads glued to it. Two series of experiments were carried out: one with $0.1 \mathrm{~mm}$ glass beads glued to the bed, the other with $0.25 \mathrm{~mm}$ glass beads. The flow discharge was constant for all experiments.

In these experiments, the dune height also showed an increase with an increasing active layer thickness and increasing sediment transport rate. However, the data do not show constant alluvial dune dimensions for large $d$, which may be an indication that alluvial conditions were not yet reached in the experiments. As the alluvial dune dimensions were unknown, the alluvial value has been estimated based on the observed dune heights and the water depth in the experiments $\left(\Delta_{0}=0.6 \mathrm{~cm}, \Lambda_{0}=7 \mathrm{~cm}\right)$.

Figure 14 shows the result of using the relative layer thickness $\left(d / \Delta_{0}\right)$ on the $x$-axis. The present experiments are still on one line, but now the data of Dreano et al. (2008) also concentrate around the same line; this shows that the relative dune height has the same relationship with the relative layer thickness for different conditions. In other words, the relative layer thickness determines the level to which the relative dune height can develop.

This result is very insensitive to the estimated value of the alluvial dune dimension in the experiments of Dreano et al. (2008). The lower limit for the alluvial dune height is the measured maximum dune height. The maximum value for the alluvial dune dimensions is approximately one-third of the water depth in the experiments. The results of Dreano et al. (2008) plot on the curve for all values between the minimum and maximum. The points only move along the curve. The assumed value for the alluvial dune height in Fig. 14 is $0.60 \mathrm{~cm}$, which is just a little larger than the maximum observed dune height of $\mathrm{Ca}$ $0.52 \mathrm{~cm}$.

The collapse of the data points to one relationship between the relative dune height or length and the relative layer thickness provides the opportunity to make a model for the dune dimensions under supply limitation. The following equations are proposed.

If a linear relationship between $L$ and $\Delta_{0}$ is assumed $\left(L=\alpha \Delta_{0}\right)$, Eq. 5 can be expressed as:

$$
\frac{\Delta}{\Delta_{0}}=1-\exp \left(\frac{-d}{\alpha_{\mathrm{h}} \Delta_{0}}\right)
$$

This relationship has one parameter to fit, $\alpha_{\mathrm{h}}$, which determines the rate of adaptation to the alluvial dune height. The relationship for the dune length (Eq. 7) is derived analogue to Eq. 6. Only the boundary condition $\Lambda=0$ for $d=0$ is not imposed. Because a wavelength can remain while $d \rightarrow 0$ as was observed in Exp. 1-3 (Fig. 3) where the bedforms formed mainly between the gravel particles. Therefore, the equation has an additional parameter $\beta$, which is used to fit the model to a finite bedform length for $d \rightarrow 0$ :

$$
\frac{\Lambda}{\Lambda_{0}}=1-\beta \exp \left(\frac{-d}{\alpha_{1} \Delta_{0}}\right)
$$

The models were fitted to the data of the present experiments using non-linear least squares fitting. The results are $\alpha_{\mathrm{h}}=0.39, \alpha_{\mathrm{l}}=0.24$ and $\beta=0.96$.
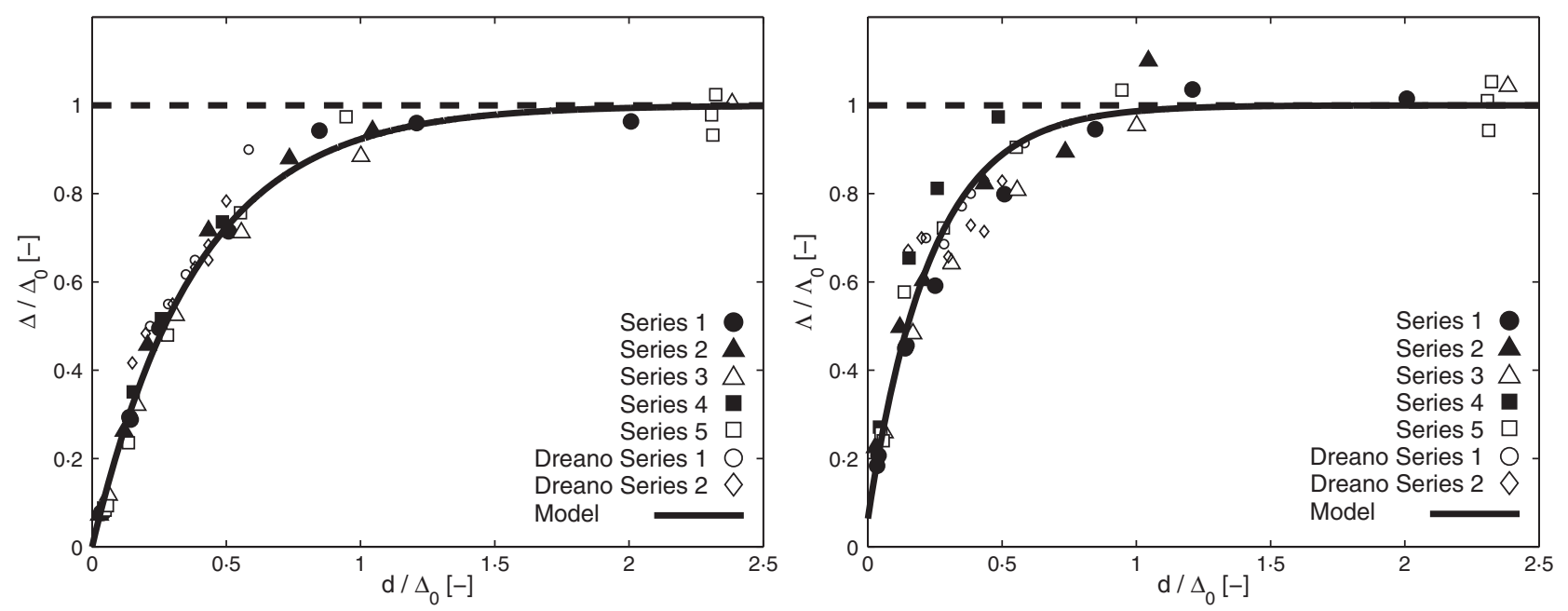

Fig. 14. (A) Left and (B) right. Relative dune height (A) and dune length (B) versus the relative layer thickness. The dashed line indicates the asymptotic value of the model, a relative dune height and length of 1. 
These results are shown in Fig. 14 as the solid line through the observations.

\section{DISCUSSION}

The main goal of this study was to investigate how the dune characteristics, most importantly the average length and height, react to a supply limitation. It was observed that the average dune height and length decrease with decreasing average layer thickness. This trend is found in other flume data and some field data as well (Kleinhans et al., 2002). The experiments of Kuhnle et al. (2006) are particularly interesting, because conditions in these experiments were comparable, but the cause of the supply limitation was different. A bed of a well-mixed bimodal sediment, which was a little finer than in the present experiment, was subjected to increasing shear stresses. The sediment mixture was only partially mobile, creating a supply limitation under the lower flow conditions. The thickness of the transport increased and the supply limitation decreased with increasing shear stress. First, under the lowest shear stress, flow parallel strips were observed. Flow transverse bedforms with increasing bedform dimensions were observed when the shear stress increased. This effect was caused by an increasing sediment availability, analogous to these experiments.

A different reaction of dune characteristics to a supply limitation was found in the Rhine in Germany. Carling et al. (2000) described the occurrence of sand dunes on top of a stable gravel lag. The available volume of sand is not enough to cover the entire bed, therefore the reach is supply limited. The dunes react to the supply limitation by forming isolated dunes rather than sedimentstarved dunes [nomenclature following Dalrymple \& Rhodes (1995) and Carling et al. (2000)]. Isolated dunes are dunes that have a varying spacing between dunes where the underlying stable base is exposed. These dunes can develop until they are depth limited, just as alluvial dunes. The supply limitation manifests itself in the larger space between dunes. Sediment-starved dunes, on the contrary, develop a smaller height and length due to the limited sediment availability. In the present observations, the dunes react to supply limitation by changing the length and height, thus forming sediment-starved dunes as surmised by Dalrymple \& Rhodes (1995). A possible cause for the difference with Carling et al. (2000) is the fact that the present experi- ments were conducted under equilibrium conditions, while, in the field, the bedforms are subjected to repeated flood waves. Carling et al. (2000) provided a conceptual model for the influence of stage history on the behaviour of dunes which describes how the bed morphology is adapting continuously to the present conditions. These non-stationary effects were not studied in the present experiments and therefore the model should be considered a model for equilibrium conditions.

\section{Range of validity}

In the present experiments, the water depth and the flow velocity were varied to incorporate their influence on the bedform dimensions into the model. The data from these experiments show that the relationship between relative bedform dimensions and the relative layer thickness is independent of water depth and flow velocity. The range of water depths in these experiments was 15 to $30 \mathrm{~cm}$. These water depths are far enough apart to clearly see their influence on the alluvial dune dimensions. The range in velocity was 0.46 to $0.67 \mathrm{~m} \mathrm{sec}^{-1}$ but the high velocity series unfortunately is not complete. The influence of the velocity was visible, but limited in range.

Scaling parameters are often valid beyond the range of observations which were used to discover them. Therefore, the dependency of the relative dune dimensions on the relative layer thickness may extend well beyond the range of parameters observed here, but this requires validation with other data sets. The fact that the data of Dreano et al. (2008) plot on the same line gives some validation for smaller dimensions, but validation is still required for larger dimensions; especially because the application of the relationship will typically be on larger-scale problems.

Bedform dimensions are also dependent on the grain-size of the transported sediment, as shown by the dependency of most alluvial dune dimension models. However, the grain-size has not been varied in the present experiment. The experiments by Dreano et al. (2008) were conducted using much finer sediment than was used for the present study. The fact that the same trend was found in these experiments suggests that the relationship may be grain-size independent as well. Finally, it is still unknown whether the geometry of the supply limited bedforms is dependent on the grain diameter of the immobile gravel layer. 


\section{Application of the model}

The authors would like to be able to predict the bed roughness in morphological and hydraulic river models based on knowledge of the characteristics of the river bed. Currently, the roughness parameters are often used to calibrate the model. By accounting for more processes in the river models, it is hoped to take a further step towards an accurately predicted roughness parameter. For roughness predictions under alluvial conditions, the roughness prediction could be based on the present models for bedform dimensions. The model presented in this paper can extend these models to incorporate partial transport conditions, provided that the volume of available sediment for bedform formation per square metre is a predictable parameter.

\section{CONCLUSIONS}

The following key conclusions are drawn from the experiments and the data analyses.

- The supply limitation clearly limits the dimensions to which dunes develop. The equilibrium bedform dimensions increase with an increasing supply of sediment, which was characterized by the active layer thickness.

- The irregularity of the dunes increases with increasing supply; or stated the other way around: the presence of the unerodable layer suppresses the development wavelengths other than the dominant wavelength. This effect is visible in the wave number spectra. Compared with the alluvial condition, wavelengths both larger and smaller than the peak wavelength are missing in a supply-limited dune field.

- The relative layer thickness determines the maximum relative dune height that can develop. This relationship is independent of both water depth and flow velocity. Therefore, these parameters can be used to formulate a model that extends the use and usefulness of existing models for dune dimensions in the alluvial regime to the supply-limited regime.

\section{ACKNOWLEDGEMENTS}

This research project, which is part of the VICI project ROUGH WATER (project number TCB.6231), is supported by the Technology Foundation STW, applied science division of the Netherlands Organization for Scientific Research (NWO) and the Technology Program of the Ministry of Economic Affairs. The laboratory experiments are funded by the Delft Cluster program 'Natural Hazards', work package A2 River Morphology (WP CT 043211). Furthermore the authors would like to thank A. Dittrich and the rest of the staff of the Leichtweiss-Institute for Hydraulic Engineering at the Technical University Braunschweig in Germany for their cooperation in the experiments. The help of masters student M. Spekkers with the flume experiments was also greatly appreciated.

\section{NOMENCLATURE}

$d$ Average layer thickness sand layer (m)

$G_{\mathrm{zz}}$ Spectral density $\left(\mathrm{m}^{3}\right)$

$h$ Water depth (m)

$L$ Characteristic length (m)

$u$ Flow velocity $\left(\mathrm{m} \mathrm{sec}^{-1}\right)$

$x$ Coordinate in length direction of flume $(\mathrm{m})$

$y$ Coordinate in width direction of flume (m)

$z$ Height coordinate above flume bottom (m)

$\alpha$ Fit parameter (-)

$\beta$ Fit parameter (-)

$\Delta$ Dune height $(\mathrm{m})$

$\Delta_{0}$ Alluvial dune height $(\mathrm{m})$

$\Lambda$ Dune length (m)

$\Lambda_{0}$ Alluvial dune length (m)

$\mu$ Mean

$\sigma$ Standard deviation

$\tau_{\mathrm{b}}$ Bed shear stress $\left(\mathrm{N} \mathrm{m}^{-2}\right)$

\section{REFERENCES}

Allen, J.R.L. (1984) Sedimentary Structures: Their Character and Physical Basis. Elsevier, Amsterdam.

Bakker, B. (1982) Determination of Bed Form Dimensions in the Sand Flume; Description and Some Results of Program DULOC (in Dutch). Technical report R 657-XLV. Delft Hydraulics Laboratory, Delft, The Netherlands.

Bendat, J.S. and Piersol, A.G. (2000) Random Data Analysis and Measurement Procedures. John Wiley \& Sons, New York.

Bennett, S.J. and Bridge, J.S. (1995) The geometry and dynamics of low-relief bed forms in heterogeneous sediment in a laboratory channel, and their relationship to water flow and sediment transport. J. Sed. Res., A64, 29-39.

Blom, A., Ribberink, J.S. and de Vriend, H.J. (2003) Vertical sorting in bedforms: flume experiments with natural and trimodal sediment mixture. Water Resour. Res., 39 (2), 1025 doi: 10.1029/2001WR001088. 
Carling, P.A., Williams, J.J., Gölz, E. and Kelsey, A.D. (2000) The morphodynamics of fluvial sand dunes in the River Rhine, near Mainz Germany. I. Hydrodynamics and sediment transport. Sedimentology, 47, 253-278.

Cartwright, D.E. and Longuet-Higgins, M.S. (1956) The statistical distribution of the maxima of a random function. Proc. Roy. Soc. London. Ser. A, Math. Phys. Sci., 237, 212232.

Chiew, Y.M. (1991) Bed features in nonuniform sediments. J. Hydraul. Eng., 117, 116-120.

Dalrymple, R.W. and Rhodes, R.N. (1995) Estuarine dunes and bars. In: Geomorphology and Sedimentology of Estuaries. Developments in Sedimentology 53 (Ed. G. M. E. Perillo), pp. 359-422. Elsevier Science B. V., Amsterdam.

Dreano, J., Valance, A., Cassar, C. and Lague, D. (2008) Experimental study of deposit morphology and sediment transport in a flume. In: Proceedings Marine and River Dune Dynamics, 1-3 April 2008, (Eds D. R. Parsons, T. Garlan and J. L. Best), pp. 97-102. University of Leeds, Leeds.

Fredsøe, J. (1982) Shape and dimensions of stationary dunes in rivers. J. Hydraul. Eng., 108, 932-947.

Gill, M.A. (1971) Height of sand dunes in open channel flows. J. Hydraul. Eng., 97(HY12), 2067-2074.

Hino, M. (1968) Equilibrium-range spectra of sand waves formed by flowing water. J. Fluid Mech., 34, 565-573.

Kleinhans, M.G., Wilbers, A.W.E., Swaaf, A. and Van den Berg, J.H. (2002) Sediment supply limited bedforms in sand-gravel bed rivers. J. Sed. Res., 72, 629-640.

Kuhnle, R.A., Horton, J.K., Bennett, S.J. and Best, J.L. (2006) Bed forms in bimodal sand-gravel sediments: laboratory and field analysis. Sedimentology, 53, 631-654.

Leclair, S. (2002) Preservation of cross-strata due to the migration of subaqueous dunes: an experimental investigation. Sedimentology, 49, 1157-1180.

McCulloch, D.S. and Janda, R.J. (1964) Subaqueous river channel barchan dunes. J. Sed. Petrol., 34, 694.

McLelland, S.J., Ashworth, P.J., Best, J.L. and Livesey, J.R. (1999) Turbulence and Secondary flow over sediment stripes in weakly bimodal bed material. J. Hydraul. Eng., 125, 463-473.

Nikora, V.I., Sukhodolov, A.N. and Rowinski, P.M. (1997) Statistical sand wave dynamics in one-directional water flows. J. Fluid Mech., 351, 17-39.

Nordin, C.F. (1971) Statistical properties of dune profiles. US Geol. Surv. Prof. Pap., 562-F, 41 p.

Nordin, C.F. and Algert, J.H. (1966) Spectral analysis of sand waves. J. Hydraul. Eng., 92, 95-114.

Simons, D.B. and Richardson, E.V. (1966) Resistance to flow in alluvial channels. US Geol. Surv. Prof. Pap., 422-I.

Tuijnder, A.P., Ribberink, J.S. and Hulscher, S.J.M.H. (2007) Predicting the occurrence of dunes under supply limited conditions. Proceedings of the River, Coastal and Estuarine Morphodynamics: RCEM 2007, Vol. I, pp. 633-639. Taylor and Francis Group, London.

Van der Mark, C.F., Blom, A. and Hulscher, S.J.M.H. (2008) Quantification of variability in bedform geometry. J. Geophys. Res., 113, doi: 10.1029/2007JF000940

Van der Zwaard, J.J. (1974) Roughness aspects of sand transport over a fixed bed. Proceedings XVth IAHR-Congress 1973, Delft Hydraulics Laboratory, Delft.

Van Rijn, L.C. (1984) Sediment transport, Part III: Bed forms and alluvial roughness. J. Hydraul. Eng., 110, 1733-1754.

Vanoni, V.A. and Brooks, N.H. (1957) Laboratory Studies of the Roughness and suspended load of alluvial streams. Report E-68. Sedimentation Laboratory, California Institute of Technology, Pasadena.

Whiting, P.J., Dietrich, W.E., Leopold, L.B., Drake, T.G. and Shreve, R.L. (1988) Bedload sheets in heterogeneous sediment. Geology, 16, 105-108.

Zhang, Y. (1999) Bed Form Geometry and Friction Factor of Flow Over a Bed Covered by Dunes. Msc Thesis, University of Windsor, Windsor.

Manuscript received 27 June 2008; revision accepted 13 January 2009 